\title{
Correction to: Resection of a plasma cell granuloma combining a conventional posterolateral left-sided thoracotomy with a minimally invasive valve approach
}

John Peder Escobar Kvitting ${ }^{1,2}$ - Ulf Hermansson ${ }^{2} \cdot$ Ingemar Vanhanen $^{2}$

Published online: 13 November 2019

(c) The Japanese Association for Thoracic Surgery 2019

\section{Correction to: General Thoracic and Cardiovascular Surgery (2019) 67:894-896 \\ https://doi.org/10.1007/s11748-018-0986-y}

The corresponding author name should read as "Kvitting JP" in PubMed and in other indexing websites.

The original article can be found online at https://doi.org/10.1007/ s11748-018-0986-y.

$\triangle$ John Peder Escobar Kvitting jpkvitting@gmail.com

1 Department of Cardiothoracic Surgery, Oslo University Hospital, Rikshospitalet, Nydalen, 0422 Oslo, Norway

2 Department of Cardiothoracic Surgery, Linköping University Hospital, Linköping, Sweden 